\title{
A FRAMEWORK FOR ESTABLISHING A HUMAN ASSET REGISTER FOR THE IMPROVED MANAGEMENT OF PEOPLE IN PHYSICAL ASSET MANAGEMENT
}

\author{
L.K. Kriege ${ }^{1 *}$, J.L. Jooste ${ }^{1} \&$ P.J. Vlok ${ }^{1}$
}

\section{ARTICLE INFO}

$\begin{array}{lr}\text { Article details } & \\ \text { Submitted by authors } & 26 \text { May } 2016 \\ \text { Accepted for publication } & 28 \text { Sep } 2016 \\ \text { Available online } & 6 \text { Dec } 2016\end{array}$

Contact details

* Corresponding author

lara.kriege@gmail.com

Author affiliations

1 Department of Industrial

Engineering, Stellenbosch

University, South Africa

DOI

http: / /dx.doi.org/10.7166/27-4-1549

\section{ABSTRACT}

People are fundamental to the success of managing physical assets. Line managers are increasingly becoming responsible for peoplemanagement activities that were traditionally placed within the human resources function, while often lacking effective peoplemanagement skills. A framework was developed to establish a human asset register to support asset managers in improving the management of people. The proposed framework provides a generic step-based approach to establishing a structured reflection of human dimensional information to facilitate the application of people management through asset managers. Structured expert interviews validated the proposed framework as providing a pragmatic method to solve the identified problem.

\section{OPSOMMING}

Mense is krities tot die suksesvolle bestuur van fisiese bates. Lynbestuurders word toenemend verantwoordelik vir menslike bestuursaktiwiteite, wat tradisioneel binne die menslike hulpbronbestuur afdeling geplaas is, maar daar is gereeld 'n tekort aan effektiewe menslike bestuursvaardighede. 'n Raamwerk is ontwikkel om ' $n$ menslike bateregister saam te stel om sodoende batebestuurders te ondersteun om die bestuur van mense te verbeter. Die voorgestelde raamwerk verskaf 'n generiese stapsgewyse benadering om 'n gestruktureerde weerspieëling van menslike dimensionele informasie te bewerkstellig om sodoende die toepassing van menslike bestuur deur batebestuurders te fasiliteer. Gestruktureerde kenneronderhoude het die voorgestelde raamwerk gevalideer as 'n pragmatiese metode om die geïdentifiseerde probleem aan te spreek.

\section{INTRODUCTION}

In today's competitive environment, businesses increasingly depend on more efficient and costeffective processes. Successful asset management is, therefore, important for organisations in various industries, in order to realise value from their physical assets, overcome current challenges, and achieve business goals [1, 2]. Asset management performance is influenced by and dependent on people, on how they are managed, and on an understanding of human dimensional characteristics. These elements are traditionally placed within the human resources (HR) area of responsibility. However, there has been a paradigm shift: such elements are becoming the responsibility of line managers [3,4] who often have insufficient skills in managing people-related issues, particularly in the technical areas of a business [5].

\subsection{Asset management}

For many organisations, physical assets represent the major cost in their operations. Their spectrum is broad, as they classify facilities and real estate, infrastructure, plant and production, mobile assets, and information technology [6]. Asset management provides systems, processes, and activities that not only ensure the most effective use of physical assets, but also improve customer 
service and reliability in line with the balance of financial objectives [7]. Its processes are gaining increasing attention in various industries. Particularly in organisations that rely extensively on the use of plant, machinery, and infrastructure, asset management plays an important role in ensuring organisational performance [8].

Asset management focuses on the effective management of an asset's entire life-cycle, from its acquisition to its utilisation, maintenance, and disposal. The focus lies not on the asset itself, but on the value it might generate for an organisation, thereby balancing performance, risks, and costs to achieve the best solutions. Additionally, asset management describes a holistic, cross-functional business practice that requires integration with various business areas and alignment with the organisation's strategic plan, as stated for example by Hastings [8], Schuman and Brent [9], and Woodhouse [10].

Given the increasing recognition of proficient asset management activities and processes as a driver for improved organisational performance, its specifications and standards have been developed over the past decade. The publication of the Public Available Specification for asset management (PAS 55) in 2004 and 2008, as well as the recently-published ISO 55000 standard series, raised the asset management field to a higher level of business relevance. These frameworks mapped out the field of asset management with a distinct focus on the development of a successful asset management system $[11,12]$.

An asset management system enables the direction, coordination, control, and optimisation of activities, and, according to the BSI [11], addresses "the diversity and complexity of assets in line with the organisation's objectives, priorities and chosen risk profile". As such, it influences the entire organisation and its stakeholders, while interlinking organisational activities and processes that would otherwise be managed and operated in isolation. Figure 1 illustrates how different asset management elements interact and influence each other in the asset management system.

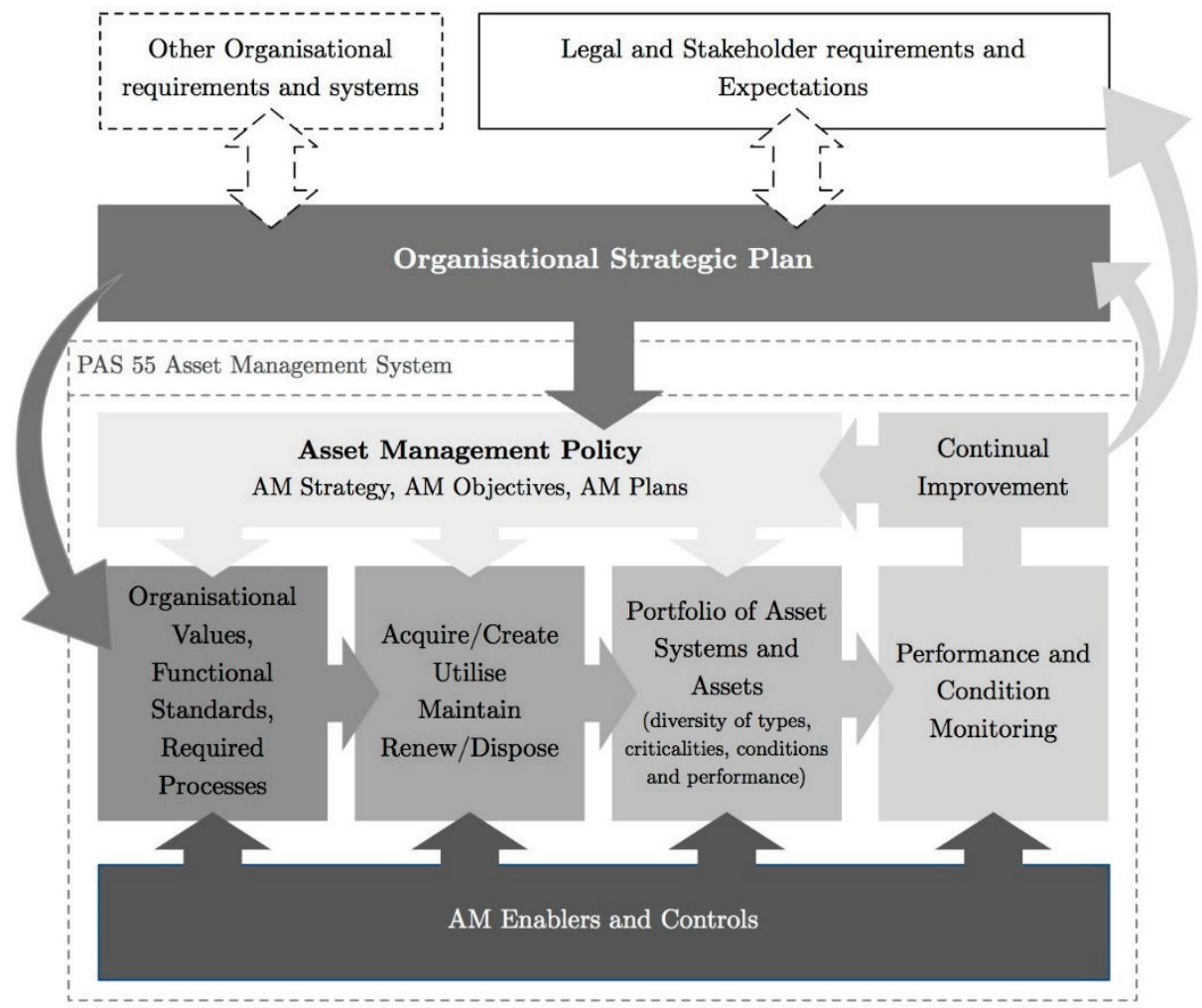

Figure 1: Asset management system (adapted from the BSI [11])

The BSI [11] draws particular attention to the integrity beyond the boundaries of the asset management system by highlighting the significance of aligning the day-to-day activities of managing assets with the organisation's strategic direction and plan. This top-down/ bottom-up alignment of 
organisational expectations with asset realities and opportunities (also called the 'line of sight') illustrates the characteristic of a successful implementation of an asset management system and, thus, effective asset management.

The asset management policy, strategy, plan, and objective represent the planning environment of the asset management system and translate the goals and mission from the organisation's strategic plan. These are implemented in the organisation's asset management through the execution of the asset management life-cycle activities (also referred to as 'implementation elements'). The planning and the implementation elements of the asset management system collaborate to ensure the aforementioned top-down/ bottom-up alignment [10,11].

\subsection{The human dimension}

Besides the strategic alignment and life-cycle-oriented approach of asset management, the human dimension (the people in asset management) is one of its most critical success factors. This element represents the 'backbone' of the asset management system [13]. As such, it provides the required skills for the successful management of physical assets (e.g., engineering, financial, technology, and communication skills). According to Amadi-Echendu [14], the human dimension determines the effectiveness and success of asset management. Various asset management scholars $[8,10,15,16]$, as well as PAS 55 and ISO 55000, highlight the importance of the effective management of people. Port et al. [15], for example, find that value-adding through people is the most important task of an asset manager. Additionally, the Institute for Asset Management [17] emphasises that "[i]t is vital to remember that people 'do' asset management, therefore, people and their knowledge, competence, motivation and teamwork can make the biggest difference to good or poor asset management".

The asset management literature and frameworks emphasise different human resource management (HRM) areas as specifically important to successful asset management. It is the case that asset management does not have an educational feed-in. Thus the management of competencies, training, and development programmes, as well as knowledge, has been shown to play a particular role not only in the establishment and sustainability of human capital, but also in the achievement of asset management strategies and goals $[8,10,14]$. Similarly, the management of key positions and filling them with talented personnel, as well as the evaluation of performance and performance measures, have been highlighted as vital to asset management success $[8,12,15]$.

People and the human dimension have been in the focus of the literature and of business practice for longer than just a couple of decades. Research in the field of strategic human resource management, which deals with the realisation of competitive advantage through people, leaves no doubt about the impact that the management of people can have on business performance [18]. Human capital (the people in an organisation and the knowledge, skills and abilities they carry) is considered to be the most significant element for production and economic growth over time [19].

Owing to the stronger strategic orientation of the HR function, and lasting dissatisfaction with and criticism of the work of HR, line managers are being given increasing responsibility for both the effective management of people and the application of $\operatorname{HR}$ practices [3, 4, 20]. Line managers, however, are most likely not experts, and lack sufficient knowledge about HR practices and their correct application and implementation, particularly in the technical area of a business [5, 16, 21]. Tsang [16] finds that this lack of knowledge is a challenge in asset management, and states that the line managers' understanding of individual and human dimensional attributes is significant for the successful management of assets.

Woodhouse [5] identifies a lack of methodologies and guidance to interlink HR and the technical business functions for improved people management. This is supported through the review of PAS 55 and ISO 55000, where both asset management frameworks highlight the importance of the people elements and provide insight into certain HRM requirements. The frameworks, however, have placed HRM responsibilities beyond their scope and that of the asset management system, and thus rely on collaboration with other organisational functions for effective people management [12]. Because HR is continuously focusing on more strategic tasks while devolving people management responsibilities to line managers, a problem arises in effective people management in asset management, such as the lack of guidance in supporting asset managers in improving the management of people. 


\subsection{Methodology and approach}

A pragmatic research method was used to address the lack of guidance for asset managers to improve people management. A thorough literature review was conducted to establish the understanding of the key concepts in the processes and activities of successful asset management, among them a detailed study of the human dimension in asset management. The literature study has shown that, in order to realise the successful management of people in asset management, line managers' understanding of human assets needs to be ensured. This resembled the existing principle of asset management in which a thorough understanding of physical asset attributes is a common prerequisite for effective decision-making.

As Hastings [8] and the BSI [22] have shown, the realisation of good asset management relies on the availability of relevant, qualitative, and timely asset information, as well as asset managers who have comprehensive knowledge of the physical assets necessary for organisational performance. A physical asset register is used, therefore, to ensure this availability and understanding of asset information and the optimal management of assets over their life-cycle [8, 17].

In the quest for a solution to the identified problem, the concept and development of a physical asset register was further investigated, and the industry was consulted to support the findings. This study addressed the problem by developing a framework to establish a human asset register, reflecting the concept of a physical asset register to manage physical assets. The framework is intended to support asset managers in improving people management by following a step-based approach to establish an understanding of people and the human dimensional characteristics and attributes. Here, the HR management practices found to be significant for asset management success, such as competency, talent, knowledge, and performance management, as well as training and development, were thoroughly reviewed. Besides the elements for the development of a physical asset register and key concepts for the successful execution of activities in an asset management system, the framework incorporated, and thus required, elements to address the HR management practices identified as significant for successful asset management. To validate the framework, structured interviews were conducted with experts in the field of asset management.

\section{A FRAMEWORK TO ESTABLISH A HUMAN ASSET REGISTER}

The development of a framework for establishing a human asset register addressed the problem. The developed framework guides asset managers in a step-wise manner to obtain sufficient information and knowledge of human assets and human dimensional attributes, in order to facilitate and improve management and decision-making about people in asset management. Furthermore, the framework is generic, while also being modifiable, and is based on unique organisational circumstances to ensure its applicability to various businesses.

Figure 2 illustrates the framework, which contains different components and four phases consisting of various steps. The steps in the second phase are divided into two step clusters. 'Phases' refer to the specific type of work that needs to be done, 'step clusters' group a number of individual steps into a logic task environment, and 'steps' describe a specific activity that needs to be performed.

The framework is reiterative, indicated in Figure 2 by the feedback arrow. This highlights the importance of applying the framework not just once, but continuously. Greater value is to be gained by reiteratively reviewing the inputs and conclusions drawn from previous applications of the framework. The reiterative nature further allows for the possibility of self-assessing the development of the people management in asset management over time.

Each step in the framework is numbered, indicating a procedural approach for applying the framework. It should be noted that, despite the illustrated sequence, the steps do not all need to be followed sequentially. Certain consecutive steps can be performed simultaneously. The interrelations between the framework steps are illustrated in Figure 3. This provides a better understanding of how the steps influence each other and how the obtained information is interlinked. The interrelations in the contextualising phase are indicated with grey arrows. These links between the organisational design (Step 1.1), the asset management context (Step 1.2), and the asset management function (Step 1.3) are regarded as indirect because the alignment between these steps occurs when they are originally developed; with regard to the framework application, the existence of these contextualising elements is expected, as the intention is to receive information from their content. The black arrows illustrate the direct interrelations of the steps, 
thus indicating the sequence of the step application. The thick grey lines indicate the generated outputs of the information collection phase.
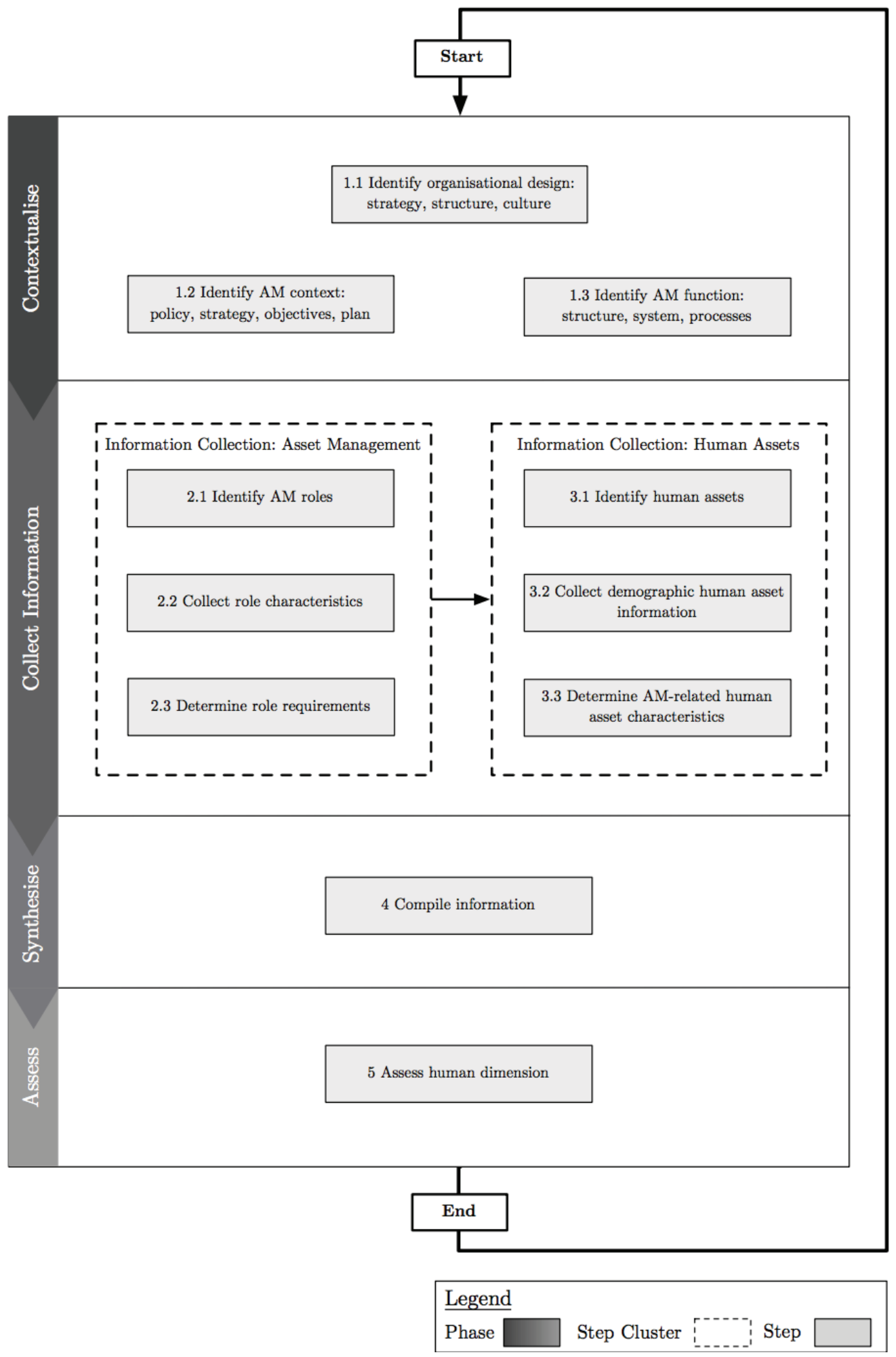

Figure 2: Framework to establish a human asset register 


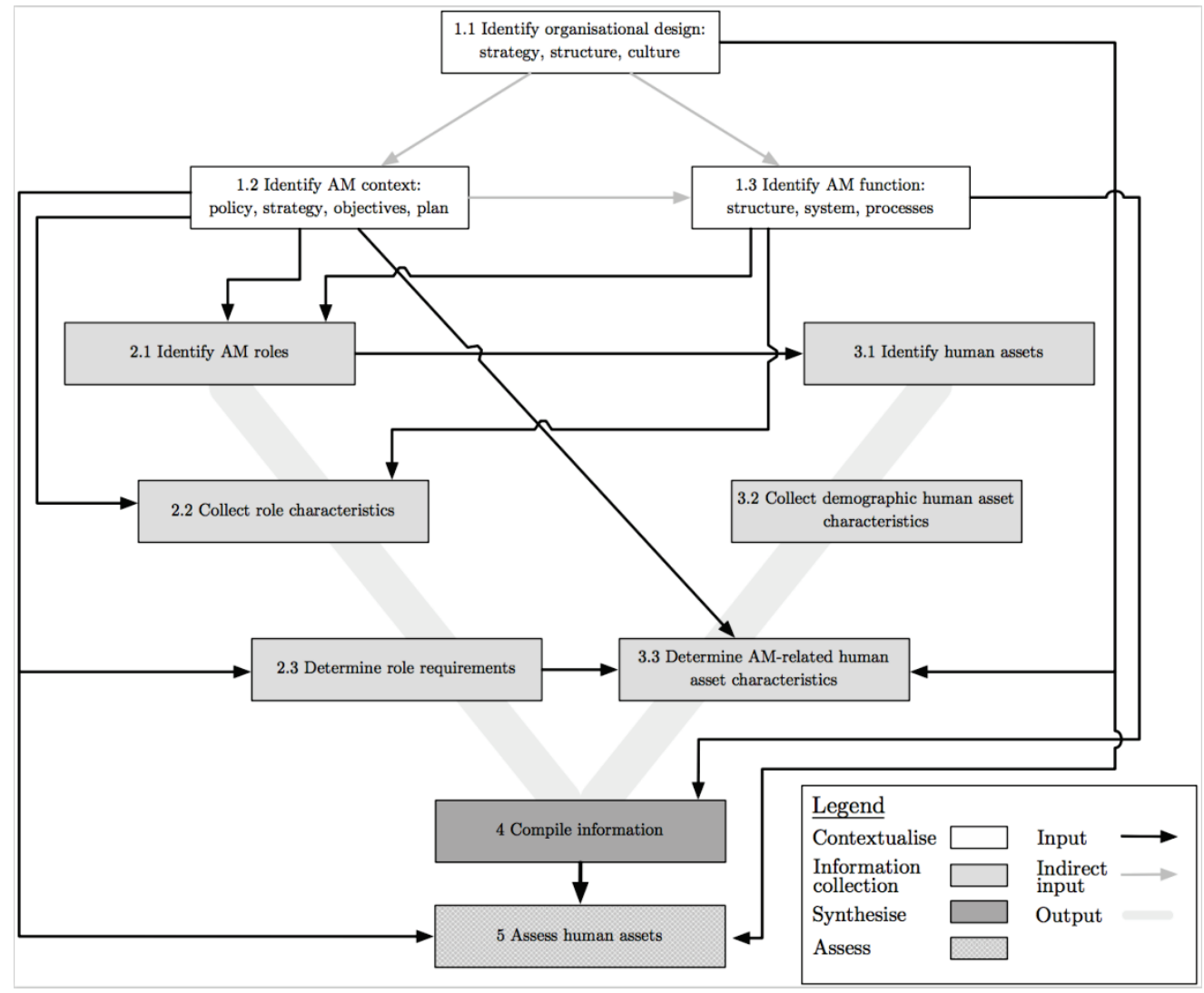

Figure 3: Interaction of framework steps

\subsection{Contextualisation phase}

The first phase, which is also the most important element of the framework, is the contextualisation phase. This element aligns the outcome of the framework with the organisational and asset management context, and enables the establishment of the 'line of sight' principle, which is significant for asset management success, and involves the alignment of the framework's activities with the organisation's overall orientation [11]. The contextualisation phase, therefore, ensures the right collection and interpretation of relevant information.

Three steps are incorporated into the contextualisation phase. Initially, in Step 1.1, the organisation's design for its established strategy, structure, and culture is identified. The alignment of asset management activities with the organisational strategic plan [11, 12, 17], the organisational culture [12] and structure [16] as an essential element in the success of asset management has been highlighted in the asset management literature. The identification of the organisation's design, therefore, represents the first step in the framework. This is followed by the analysis of the asset management environment with regard to its overall context in the asset management policy, strategy, objectives, and plan (Step 1.2). These asset management planning elements ensure the translation of the organisational goals and mission into the asset management context, thus providing further support for the top-down/bottom-up alignment in the organisation-specific asset management system [11]. An understanding of these planning elements, therefore, needs to be ensured for the implementation of any activities related to the management of assets $[11,12,17]$.

Step 1.3 refers to the identification of asset management functional details of its structure, system, and processes. Unlike other business functions, asset management is usually not clearly allocated within the organisational structure [8]. This step thus ensures further insight into the organisation's unique asset management environment. 
By addressing the contextualisation of the framework, these initial three steps do not provide direct output to the register, but rather provide a background for data collection and the interpretation of asset management and human asset information.

\subsection{Information collection phase}

The second phase is divided into two different step clusters: (a) the asset management environment (Steps 2.1 to 2.3), and (b) the human asset environment (Steps 3.1 to 3.3). This enables a clear differentiation between the two different activity areas of the information collection phase, and provides an improved overview of the various structural framework parts. The information collection within these two step clusters forms the main part of obtaining the framework output.

\subsubsection{Asset management environment}

Initially, the collection of information about the asset management environment is suggested in order to define fully the context within which a human asset is located. The information obtained in this step cluster does not represent the key information of the framework output; it is intended to facilitate the human asset register's structural development, provide background understanding, and assist in the identification and collection of information on human assets as addressed in the next step cluster.

In Step 2.1, all asset management roles integrated into the asset management function that support the asset management strategy and goals are identified. This step provides the basis for Step 3.1, as it facilitates the identification of human assets. The combination of Steps 2.1 and 3.1 resembles the requirement of identifying all significant assets in establishing a physical asset register. For improved insight into the placement of the individual roles in the asset management context, the asset management roles are further characterised by identifying role-describing information, which is covered in Step 2.2. This includes elements such as the role title, the functional role environment, unit or team, the role level, and the role significance in terms of key or non-key functions.

The last step in this step cluster (Step 3.3) addresses the identification of role-specific requirements. The identification and understanding of role requirements is vital to both the effective application of HRM and the achievement of the particular role's objectives, and thus to the delivery of asset management and organisational goals [11, 23, 24]. The role requirements addressed in this framework are competencies that relate to (a) qualifications, (b) technical skills, and (c) behavioural skills, as well as the performance goals of the respective roles as bottom-line measures.

\subsubsection{Human asset environment}

The human asset environment represents the second cluster of the information collection phase. In this cluster, the relevant information of human assets is obtained, which - in addition to the asset management information - supports and improves the understanding of the human dimension in the asset management environment.

Step 3.1 aims to identify all relevant human assets in the asset management environment, based on the roles listed in Step 2.1. These two steps resemble the development process of a physical asset register, in which all significant physical assets are initially identified and their identification number listed in the respective register [17]. In Step 3.2, demographic information of the human assets is collected to provide broader insight into their general characteristics and further to enable the assessments of the human dimension in Step 5. This step is aligned with the collection of physical asset attributes and information in the establishment of a physical asset register in order to provide sufficient knowledge about the assets that lie at the centre of attention [17]. Relevant demographic data of human assets includes, but is not limited to, name, gender, age, organisational tenure, absence/sick leave, and overtime [25].

In Step 3.3, the final step of the information collection phase, asset management-related human asset characteristics are determined. The output of this step is based on the HRM practices identified as significant for asset management success from reviewing the asset management literature and frameworks [i.e., 8, 10-12, 14, 15, 17]. In this step, the main information is collected to support the improved understanding of human asset and human dimensional characteristics. The information collection is aligned with the areas of competencies, knowledge, training, and development, as well as performance and talent management. The outputs of this step might vary according to the organisation's unique operational and strategic context.

The following examples should be addressed in Step 3.3: 
- Identification of talents: The awareness of whether individuals are characterised as highpotential or high-performer candidates (talent) is important to ensure the right allocation of personnel to key positions and to facilitate the management of talents. This is a significant practice for organisations in the process of adding value and achieving operational excellence, as shown, for example, by Collings and Mellah [26] and Gallardo-Gallardo et al. [27], while contributing to asset management success [12].

- Competencies availability: The management of competencies increases competitive advantage, innovation, and effectiveness in the organisation [28]. As stated by the IAM [23, 24], the awareness of possible competency gaps among managers is significant in effectively managing human assets and achieving asset management goals. Therefore the human assets' available qualifications, behavioural skills, and technical skills need to be identified and evaluated against the required role competencies gathered in Step 2.3. Gaps should be illustrated.

- Performance achievement (bottom-line measures): The achievement of performance measures, which were identified in Step 2.3, is to be evaluated for each human asset and illustrated appropriately. Evaluation and control of performance measures facilitates steady capacity and safety within asset management [15] and supports the management of people in administrative and developmental decisions [29, 30].

- Training and development initiatives: Available programmes and initiatives are to be listed and their success monitored in order to increase both the awareness of training and development possibilities and their effectiveness. This area has been highlighted as one of the most significant elements for successful asset management $[8,10,12]$. Its purpose is to address the identified deficiency areas of individuals, as well as their personal growth [31].

- Key knowledge information: Key knowledge of individuals about asset management processes, structures, activities, etc. is to be identified and displayed, and further characterised as specific, unspecific, explicit, or tacit knowledge. Factors such as employee mobility, turnover, and high competitive business environments have been expressed as a need for organisations to capture, retain, and share their knowledge, skills, and abilities in an effort to prevent their loss when employees leave the organisation [32,33]. As asset management does not have an educational feed-in, knowledge management - and especially the prevention of knowledge loss - is significant. The awareness of these factors facilitates the prioritisation of knowledge retention and management in preventing significant knowledge loss for the organisation [8, 17].

It should be noted that this list is not exhaustive. Organisations are encouraged to identify additional elements of value to asset managers for the improved management of people.

\subsection{Synthesis phase}

The synthesis phase contains Step 4, which addresses the compilation of the collected information into a register. Step 4 ensures a structured basis of relevant human asset characteristics, which in turn provides an organised overview of the current human dimensional situation and facilitates further evaluation of the human assets and the human dimension. The synthesis of the information can occur concurrently with the other steps in the information collection phase.

Organisations need to ensure that the structure of their human asset register aligns with their organisational logic and requirements. In smaller organisations, a structure using asset management roles might be less beneficial because some individuals might fulfil multiple asset management roles.

\subsection{Assessment phase}

This last phase, Step 5, is an assessment step. It is integrated into the framework to highlight the importance of applying and using the information collected throughout the previous steps. Step 5 assesses the information compiled during Step 4, and detects deficiencies that require specific attention in the human dimension. By highlighting deficiencies, asset managers are made aware of specific areas in the human dimension that need to be addressed, possibly encouraging an improved and more targeted application of HRM practices. Identifying opportunity areas (areas in the human dimension that are performing strongly) is included in Step 5. These can be used as a benchmark against other individuals or units in an organisation, and help to find solutions to overcome the current deficiencies. 
Additionally, Step 5 initiates a periodic self-assessment of the development of quality people management in asset management over time. The captured information should be updated periodically to provide knowledge of individual development trends and the success of previous management initiatives. The following elements are examples that can be reviewed in a human asset register to detect deficiency and opportunity areas:

- A summary of the overall competencies and performance measures results, available in form of a rating scale. This illustrates the contribution that individuals or specific units or teams make to the organisation, where competency deficiencies and opportunities lie, and in which competency categories (qualifications, or behavioural or technical skills) these can be identified.

- The compatibility between key positions and key personnel. This will indicate possible deficiencies, and highlight the requirements for improvement to achieve the right fit between a position and an individual.

- The reflection of the skill and performance development of individuals over a period of time, which can identify the success or failure of previous management initiatives.

- The determination of skill shortages by identifying what types of competencies and skills are lacking in the organisation's asset management environment or a specific unit or team, and which skills are significant for organisational performance.

- The identification of a knowledge risk factor that indicates the importance of retaining the knowledge of individuals or groups in terms of distinct categories (i.e., high priority, priority, high importance, and importance). The likelihood of losing a human asset within a specific time frame should therefore be reviewed, as well as the person's knowledge criticality or uniqueness to the organisation, including an estimated level of effort required to replace this particular individual.

\section{FRAMEWORK VALIDATION}

Mining organisations are strongly reliant on the performance of their physical assets. Asset management experts from one of the world's largest mining companies, who are exposed to the organisation's asset management functions, processes, and activities on a daily basis, assisted in addressing the framework's validity. The validation was conducted in the form of structured interviews with four of the organisation's asset management experts.

Each interview was held on a one-on-one basis, using the following structure:

- Presentation of the research methodology, including background, problem statement, and approach of the study;

- Presentation of the framework, containing an explanation of each step and the steps' interrelations in the framework;

- $\quad$ Discussion of possible queries or misunderstandings; and

- $\quad$ Issuing a questionnaire to collect the data required to validate the framework.

The questionnaire serves as a measure of face validity. It is to identify whether or not the proposed framework addresses the problem that has been researched, its strength, weaknesses, potential areas of improvement, and the correctness of its structural elements. The following paragraphs illustrate the results from the questionnaire.

Overall, the participants endorsed the potential of the framework as guidance to support asset managers in improving the management of people in asset management. One participant stated: "Currently, we only have individual building blocks that don't fit together; the framework provides more structure and depth of the current situation."

Another participant remarked: "There is a lot of value in having a human asset base to analyse what is currently going on. There is definitely a need for a framework to assist in determining your assets and what their characteristics are."

Furthermore, one participant said that "the framework can provide output on how people have to change to fit current as well as future roles and requirements. Line managers can therefore get the most out of their candidates. I can see this framework as very useful to accommodate development and changes that are required to ensure that people fit into the role requirements in 
the long-term perspective; it will support the preparation of our human assets. Right now the perception is either someone fits or doesn't fit. This framework can accommodate the time that is required to mould people in the right direction."

With respect to the frequent lack of people skills among managers from technical and engineering backgrounds, all participants affirmed the framework's potential to guide such managers. One of the participants clearly stated: "If leadership and people management does not come naturally, the framework provides good guidelines; this is especially relevant for managers with technical backgrounds."

The participants were asked to highlight strong and outstanding points in the proposed framework. Elements that were identified included the following:

- The contextualising phase: "it sets the scene; without that you wouldn't be able to get something out of the process."

- The alignment of the framework with the concept of a physical asset register: "If there is no register for physical assets, then how does an engineering planner do anything? The same is therefore required for human assets."

- The structure of the framework and the guidance it provides.

- The continuous feedback loop of the framework.

- The final assessment step: "benchmarking and data mining can be performed, which is not possible without a structured database or at most would have limited success".

Participants were further asked to identify weak points in the proposed framework in order to detect possible fundamental shortcomings that could influence the potential of the framework to address the identified problem properly.

Two participants stated that the framework helps to identify where improvements are needed; however, how these should be addressed does not necessary follow from its application. Another participant identified the failure to address the more emotional aspects of people that reflect their unique circumstances; the participant reflected that " $[t]$ hings that happen in private lives can influence performance constantly and this should be recognised when it comes to the management of people." This was reiterated by another participant, who stated that the framework does not express exactly what it is that "makes people tick".

Furthermore, one of the participants raised a concern about the focus of the framework on the identification of deficiency areas, as the framework should also be seen as a tool "for showing opportunities and pointing out positive things, things that are already working." The participant stated that these opportunity areas could then serve as guidance for other organisational areas that need improvement.

Further concerns were raised about the strong focus of the framework on the current situation in the human dimension without explicitly highlighting the opportunity of a forward outlook with an emphasis on future requirements.

Overall, the participants agreed that the architectural aspects are well articulated, as illustrated in Figure 4 . With reference to the alignment between the user's perception of the step content and the suggested step content, the participants indicated a deficiency. This is also reflected in the last question, discussed below, which addresses the possibilities for improving the framework.

Finally, the participants were asked to provide suggestions about how the framework could be improved and so potentially enhance the fulfilment of its purpose. Three of the four participants stated that a brief user guide should be made available to ensure the full understanding of the activities required in each step of the framework. 


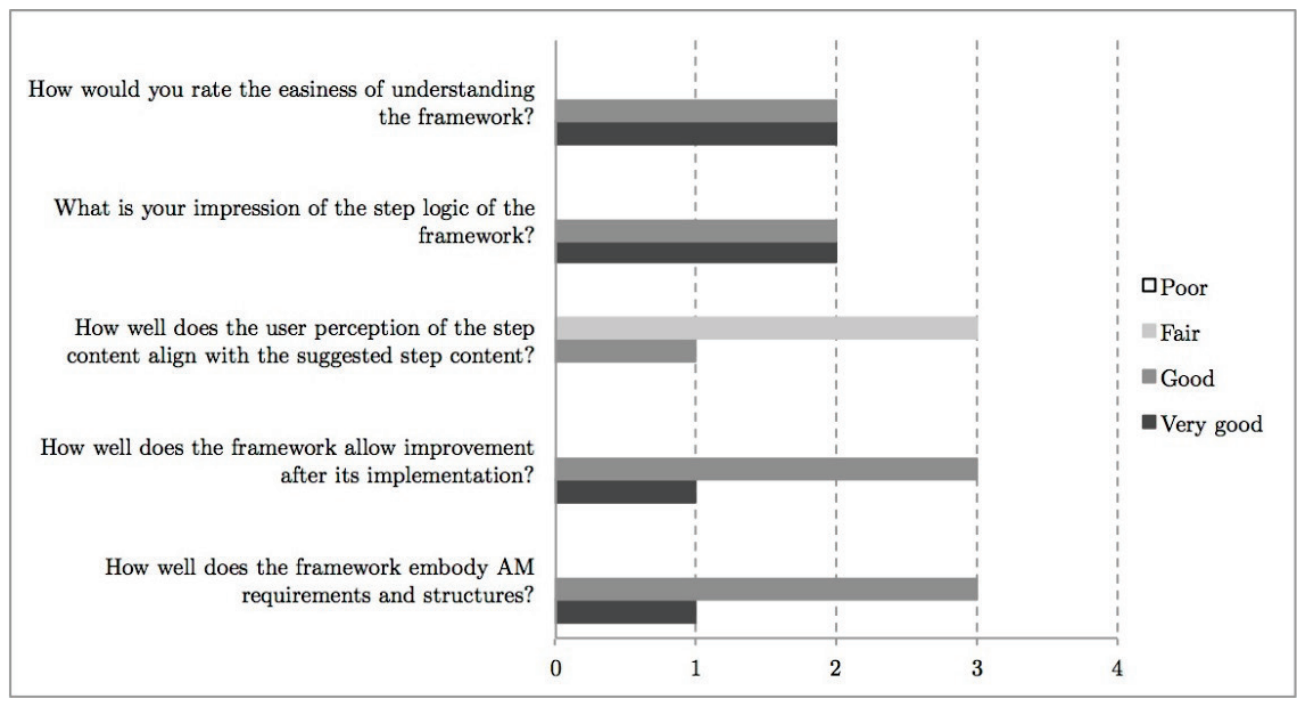

Figure 4: Participants' responses on the architectural aspects of the framework

A range of different improvement suggestions were made by the participants in the interview. One highlighted the improvement aspects by illustrating different business scenarios in which the framework could be used. The participant stated: "Right now, it is very generic, which is good, but there might be a difference in approaching the steps when organisations are at different phases such as small regional based business, large national business, multi-commodity business, global international business, developing a new business, restructuring, or if it's already in a stage of a mature organisation. Furthermore, the framework would support not only businesses but could apply to a school and their teachers, a university and the lecturers, municipalities, etc." Another suggestion was for a stronger alignment of the framework with a physical asset register by identifying the equivalents of the physical asset register's content to the human dimension.

\section{DISCUSSION}

The purpose of this study was to address the problem of the lack of guidance in asset management to support asset managers in improving the management of people. This problem results from a combination of various circumstances. People are identified as one of the most determining factors between successful and unsuccessful asset management. Thus the effective management of human assets is vital. The existing shift of people management responsibilities from the HR function to line managers is a challenge to effective people management. Line managers, especially those in the technical areas of a business, often lack sufficient HRM skills. Additionally, the asset management body of knowledge provides no guidance for improving their people management. Therefore, a stepbased and generic framework was developed to establish a human asset register that could enable the improved management of people in asset management. The framework steps were based on the elements required for the successful execution of activities and processes in the asset management system, the principles of developing a physical asset register, and the information about HRM practices identified as significant in asset management.

The initial contextualisation steps enable the user fully to understand the organisation and its asset management function's context and purpose. Following these steps ensures the correct collection and interpretation of information, and enables the user to address people management in alignment with the overall organisational and asset management goals. The next six steps guide the collection of information, and advise on the HRM areas that most important in ensuring successful asset management. These steps enable asset managers to focus on key areas in people management and to ensure that the required information is available. Finally, the last two steps demonstrate how the information can be compiled and used to address people management effectively. It is important to assess the human dimension and to identify deficiencies and opportunities. This will encourage an improved and targeted application of people management on a continuous basis.

Overall, the validation process demonstrated that the proposed framework provides guidance for asset managers to improve the management of people in asset management. Those interviewed 
endorsed the potential of the proposed framework, its structure, and the guidance it provides to receive better information about human dimensional elements, especially where line managers lack people management skills.

As the validation proved the usefulness and functionality of the framework, it also demonstrated that the subject of managing people presents both challenges and opportunities. The research participants alluded to the fact that more research is required in the field of people management especially research that will lead to better a understanding and integration of the emotional side of employees in people management practices, as well as the translation of these factors into practice. With regard to line managers in the technical areas of a business, improved support in how to manage people in their actions and application should be provided to ensure the successful management of human assets.

The study was subject to limitations that should be recognised in this discussion. The small number of participants in the validation process led to a degree of diversity among the responses about the framework's strong points and weak points, and about suggestions for improvement. To ensure a greater representativeness and the better external validity of the study, a larger number of experts from different industries should be consulted. Therefore it is recommended that the proposed framework be implemented in the field in order to ascertain whether the established validity can be sustained.

\section{CONCLUSION}

The results of this study show that the proposed framework to establish a human asset register provides a pragmatic method to improving people management in asset management. The framework provides a structured and objective presentation of relevant human asset characteristics and attributes that would enable organisations to address their people management proactively. Given that the effective management of people is a proven and significant success factor for organisational performance, industries that rely in particular on skilled technical managers will benefit from the study, owing to the fact that these managers often lack skills in managing people. The framework provides step-by-step guidance that establishes fundamental understanding and knowledge about relevant human assets. The outcome of its application points to current deficiencies and opportunities in the human dimension, and supports both development and change, to ensure a long-term fit between people, asset management, and organisational requirements.

The study enhanced the focus to consider strongly the relevance of human assets in asset management and generally in technical areas of a business. It further emphasised the responsibilities of line managers in people management, which is not considered in asset management. Although the research into people management has addressed the shift of HR responsibilities to line managers and the importance of facilitating the effective management of people in the technical areas of a business, future research still has much to offer in providing suitable solutions and support for the right management of people, particularly in technical industries.

\section{REFERENCES}

[1] Emmanouilidis, C., Liyanage, J.P. \& Jantunen, E. 2009. Mobile solutions for engineering asset and maintenance management. Journal of Quality in Maintenance Engineering, 15(1), pp. 92-105.

[2] McGlynn, J. \& Knowlton, F. 2011. Asset classes and the world of life-cycle asset management. In: Campbell, J.D., Jardine, A.K. \& McGlynn, J. (Eds.) Asset management excellence: Optimizing equipment life-cycle decisions. Taylor and Francis Group, pp. 11-22.

[3] Kulik, C.T. \& Perry, E.L. 2008. When less is more: The effect of devolution on HR's strategic role and construed image. Human Resource Management, 47(3), pp. 541-558.

[4] Cappelli, P. 2013. HR for neophytes. Harvard Business Review, October, pp. 25-27.

[5] Woodhouse, J. 2004. Joining up the jigsaw puzzle - Coordinating the implementation of new practices, methodologies, education and culture change, all in a sustainable manner. Available from http: / /www.twpl.com/twpl-library/asset-management-white-papers/joining-jigsaw-puzzle-coordinatingimplementation-new-practices-methodologies-education-culture-change-sustainable-manner/. Accessed on 10 March 2015.

[6] Campbell, J.D., Jardine, A.K. \& McGlynn, J. 2011. Asset management excellence: Optimizing equipment life-cycle decisions. Taylor and Francis Group.

[7] Too, E.G. 2010. A framework for strategic infrastructure asset management. Definitions, Concepts and Scope of Engineering Asset Management, 1(1), pp. 31-62. 
[8] Hastings, N.A.J. 2010. Physical asset management. Springer.

[9] Schuman, C.A. \& Brent, A.C. 2005. Asset life cycle management: Towards improving physical asset performance in the process industry. International Journal of Operations \& Production Management, 25(6), pp. 566-579.

[10] Woodhouse, J. 2007. Joining the jigsaw puzzle - PAS 55 standards for the integrated management of assets. Maintenance and Asset Management, 12(1), pp. 12-16.

[11] BSI. 2008. PAS 55-1:2008, Part 1: Specification for the optimized management of physical assets. British Standards Institution.

[12] BSI. 2014. BS ISO 55000 series - Asset management, BS ISO 55000:2014, BS ISO 5500:2014, BS ISO 55002:2014. BSI Standards Limited.

[13] Kriege, L. \& Vlok, P.J. 2015. Human resources within ISO 55000 - The hidden backbone to the asset management system. In: Amadi-Echendu, J., Hoohlo, C. \& Mathew, J. (Eds.) 9th WCEAM Research Papers. Springer, pp. 435-446,.

[14] Amadi-Echendu, J. 2010. Behavioural preferences for engineering asset management. Definitions, Concepts and Scope of Engineering Asset Management, 1(1), pp. 347-355.

[15] Port, T., Ashun, J. \& Callaghan, T.J. 2011. A framework for asset management. In: Campbell, J.D., Jardine, A.K. and McGlynn, J. (Eds.) Asset management excellence: Optimizing equipment life-cycle decisions. Taylor and Francis Group, pp. 23-48.

[16] Tsang, A.H. 2002. Strategic dimensions of maintenance management. Journal of Quality in Maintenance Engineering, 8(1), pp. 7-39.

[17] IAM. 2014a. Asset management - An anatomy. Tech. Rep., Institute of Asset Management.

[18] Colakoglu, S., Hong, Y. \& Lepak, D.P. 2010. Models of strategic human resource management. In: Wilkinson, A., Bacon, N., Redman, T. \& Snell, S. (Eds.) The SAGE handbook of human resource management. SAGE Publications.

[19] Blair, M.M. 2011. An economic perspective on the notion of human capital. In: Burton-Jones, A. \& Spender, J.-C. (Eds.) The Oxford handbook of human capital. Oxford University Press, pp. 49-70.

[20] Becker, B.E. \& Huselid, M.A. 2006. Strategic human resources management: Where do we go from here? Journal of Management, 32(6), pp. 898-925.

[21] Gilbert, C., De Winne, S. \& Sels, L. 2011. The influence of line managers and HR department on employees' affective commitment. The International Journal of Human Resource Management, 22(8), pp. 1618-1637.

[22] BSI. 2008. PAS 55-2:2008, Part 2: Guideline for the application of PAS 55-1. British Standards Institution.

[23] IAM. 2014. The IAM competency framework - Guidance: Version 3.0. Institute of Asset Management.

[24] IAM. 2014. The IAM competency framework - The requirements: Version 3.0. Institute of Asset Management.

[25] Armstrong, M. \& Taylor, S. 2014. Armstrong's handbook of human resource management practice. Kogan Page Publishers.

[26] Collings, D.G. \& Mellahi, K. 2009. Strategic talent management: A review and research agenda. Human Resource Management Review, 19(4), pp. 304-313.

[27] Gallardo-Gallardo, E., Dries, N. \& González-Cruz, T.F. 2013. What is the meaning of 'talent' in the world of work? Human Resource Management Review, 23(4), pp. 290-300.

[28] Draganidis, F. \& Mentzas, G. 2006. Competency-based management: A review of systems and approaches. Information Management \& Computer Security, 14(1), pp. 51-64.

[29] Brown, M. \& Lim, V.S. 2010. Understanding performance management and appraisal: Supervisory and employee perspectives. In: Wilkinson, A., Bacon, N., Redman, T. \& Snell, S. (Eds.) The SAGE handbook of human resource management. SAGE Publications Ltd, pp. 191-210.

[30] Kondrasuk, J.N. 2011. So what would an ideal performance appraisal look like? Journal of Applied Business and Economics, 12(1), pp. 57-71.

[31] Wilson, J.P. 2005. Human resource development: Learning and training for individuals and organizations. Kogan Page Limited.

[32] Schutz, P.F. \& Carpenter, D.A. 2008. Critical considerations of talent management and knowledge management for effective HR planning. In: Vance, C.M. and Vaiman, V. (Eds.) Smart talent management - Building knowledge assets for competitive advantage. Edward Elgar Publishing Limited, pp.19-32.

[33] Brewer, P.D. \& Brewer, K.L. 2010. Knowledge management, human resource management, and higher education: A theoretical model. Journal of Education for Business, 85(6), pp 330-335. 